\title{
Investigation of Seiche Oscillations in the Adjacent Bays by the Example of the Sevastopol and the Quarantine Bays
}

\author{
Yu. V. Manilyuk*, D. I. Lazorenko, V. V. Fomin \\ Marine Hydrophysical Institute of RAS, Sevastopol, Russian Federation \\ *uvmsev@yandex.ru
}

Purpose. The paper is aimed at studying the seiche structure in the adjacent bays' system of real configuration.

Methods and Results. The response of the Sevastopol and Quarantine bays (Black Sea) to sea level fluctuations set at the open boundary of the computational domain has been studied. A number of random harmonics within the range of the eigen periods of these bays were used as fluctuations. The ADCIRC numerical model was applied for simulating. The numerical experiments were performed for three ranges obtained from the analytical estimates: 30-52, 8-30 and 1-15 min. The energy-bearing periods of seiche oscillations were revealed for both bays. The mutual influence of these bays was also studied.

Conclusions. The above mentioned wave disturbances lead to generation of the seiche oscillations in the bays. For the Sevastopol Bay, their periods are 48, 22, 16, 10 and 6 min, for the Quarantine Bay 11.4 and $4.8 \mathrm{~min}$. The number of the generated modes is determined by the interval of the wave disturbance periods. The bays have a mutual influence on each other due to the wave energy exchange through their entrances. At that intensity of the eigen modes of the Sevastopol Bay penetrating the Quarantine Bay can exceed intensity of those of the Quarantine Bay. In both bays, the seiches with the largest amplitudes are induced by the disturbances, the periods of which are in the interval 30-52 min.

Keywords: Sevastopol Bay, Quarantine Bay, seiches, resonant oscillations, numerical modeling, ADCIRC numerical model.

Acknowledgments: the investigation was carried out within the framework of the state task of Marine Hydrophysical Institute, RAS on theme No. 0827-2018-0004 "Complex interdisciplinary investigations of the oceanologic processes conditioning functioning and evolution of the Black and Azov seas' coastal zones” at partial RFBR support (project No. 18- 05-80035).

For citation: Manilyuk, Yu.V, Lazorenko, D.I. and Fomin, V.V., 2020. Investigation of Seiche Oscillations in the Adjacent Bays by the Example of the Sevastopol and the Quarantine Bays. Physical Oceanography, [e-journal] 27(3), pp. 242-256. doi:10.22449/1573-160X-2020-3-242-256

DOI: 10.22449/1573-160X-2020-3-242-256

(C) Yu. V. Manilyuk, D. I. Lazorenko, V. V. Fomin, 2020

(C) Physical Oceanography, 2020

\section{Introduction}

There is a system of bays having various configurations, sizes and bathymetry in the coastal zone of Sevastopol. The Sevastopol Bay (length $7 \mathrm{~km}$, average width $1 \mathrm{~km}$ and average depth $11.7 \mathrm{~m}$ ) is the largest one. To the west adjacent to it is the Quarantine Bay (length $1.6 \mathrm{~km}$, average width $0.2 \mathrm{~km}$, average depth $8.2 \mathrm{~m}$ ) (Fig. 1).

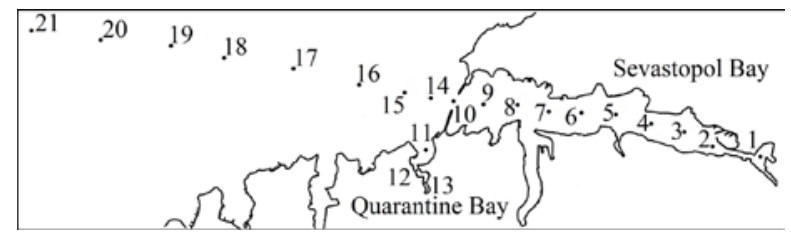

F i g. 1. System of the Sevastopol bays and location of the points, at which the sea level fluctuations were analyzed 
Despite the importance of bays for Sevastopol, they have not yet been studied enough. Oceanologic research was carried out mainly in the Sevastopol Bay [1]. Sea level fluctuations were recorded using a tide gauge at the Marine Hydrometeorological Station Sevastopol. Examples of typical mareograms are shown in Fig. 2 [2]. The characteristics of the currents in the Sevastopol Bay were measured by ADCP probe during Marine Hydrophysical Institute expeditions [3]. Current fluctuations occurring at the bay entrance with a period of about 60 minutes were monitored during these expeditions. In [4], a numerical calculation of the eigen modes of the Sevastopol Bay was carried out. Based on mathematical modeling the currents in this bay were studied in [5] and the dynamics of the contaminating impurity spread - in [6]. There are no observational data on hydrophysical parameters for the Quarantine Bay.
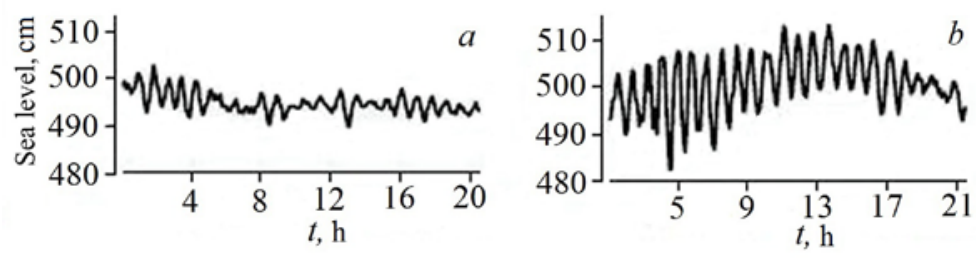

F i g. 2. Observed mareograms for the Sevastopol Bay [2, p. 249]: a) - "background" seiches, $b$ ) intensive seiches

In bays seiches are generated either by direct action of atmospheric disturbances on the bay surface, or by disturbances coming to the bay through open boundaries. Disturbances coming from the open sea have different time scales. Seiches observed in bays and gulfs of the Black Sea have periods from several minutes to 1-2 hours and amplitudes up to 20-25 cm [7]. Seiches of small periods (2-3 min) are more often recorded during the storm [7] and are caused by the transformation of storm waves in the coastal zone. So, in [8] it is indicated that as a result of the nonlinear interaction of storm waves with periods of 8-10 s, infragravity waves with characteristic periods of 30 to $300 \mathrm{~s}$ appear. Seiches of longer periods (15-20 min) are caused by sharp fluctuations of atmospheric pressure [7]. Seiches of this type are most often generated during the passage of cyclones, especially their peripheries, determining the wind amplification [7]. If the periods of disturbing oscillations coincide with the natural periods of the bay, resonance amplifying the oscillations is possible. In bays, one of the dangerous phenomena associated with seiches is harbor oscillations (harbor currents) [8]. The works [9, 10] study the conditions for the appearance of harbor oscillations in a number of Sevastopol bays.

The study of the mutual influence of adjacent bays is of great practical importance. So, in [11], the interaction of two model bays with the characteristic dimensions: the Sevastopol Bay and Quarantine Bay, was considered. In [12], the interaction of adjacent large and smaller bays was studied by the example of the Ciutadella and Platja Gran inlets located on the west coast of Menorca Island, one of the Balearic Islands in the Western Mediterranean. 
The results of studies of the mutual influence of two bays, obtained in [13] based on laboratory experiments using a hydraulic model are of undoubted interest. The promising experimental studies of seiche oscillations in the Far East bays and gulfs should be mentioned. They were carried out by the Pacific Oceanographic Institute and the Institute of Marine Hydrophysics and Geology, Far Eastern Branch of the Russian Academy of Sciences using laser interferometers and laser hydrophones [14-16]. In the aforementioned works, the natural periods of a large number of Far Eastern bays were established.

The present paper is aimed to study the resonant response of the Sevastopol and Quarantine bays to disturbances coming from the open sea, and the mutual influence of these bays on each other.

\section{Numerical model and algorithm for estimating periods of seiche oscillations}

To study seiche oscillations in the Sevastopol and Quarantine bays, the numerical hydrodynamic Advanced Circulation Model for Shelves Coasts and Estuaries (ADCIRC) was used in this work; its detailed description is given in [17-20]. Below the model variant based on linearized depth equations of motion averaged over depth without taking into account the Coriolis force was used:

$$
\frac{\partial U}{\partial t}+g \frac{\partial \eta}{\partial x}=A_{h} \frac{\Delta q_{x}}{H}, \quad \frac{\partial V}{\partial t}+g \frac{\partial \eta}{\partial y}=A_{h} \frac{\Delta q_{y}}{H}, \quad \frac{\partial \eta}{\partial t}+\frac{\partial q_{x}}{\partial x}+\frac{\partial q_{y}}{\partial y}=0 .
$$

Here $U, V$ are the depth-average components of the velocity vector along the $x$ and $y$ axes, respectively; $t$ is the time; $\eta$ is the water level in the basin; $H=h+\eta$ is the dynamic depth; $\Delta$ is the Laplace operator on spatial variables; $A_{h}$ is the horizontal turbulent viscosity coefficient; $q_{x}=U H, q_{y}=V H$ are the full flow vector components.

On the solid side walls of the computational domain, the boundary nonleakage condition was used. To exclude the friction nonlinearity effect at the bottom, a boundary sliding condition was set.

Numerical algorithm of the ADCIRC model is based on the finite element method using triangular elements with linear basis functions. To reduce the computational noise level during the numerical integration of system (1), the continuity equation is represented in the Generalized Wave Continuity Equation (GWCE) form [17]. GWCE computational noise level is controlled by a parameter $\tau_{0}$.

Simulation of seiche oscillations in the system of Sevastopol bays was carried out on an unstructured computational grid of 56,354 nodes (107,202 finite elements), shown in Fig. 3. For the numerical algorithm stability, the integration time step was $\Delta t=0,025 \mathrm{~s}$, the turbulent viscosity coefficient $A_{h}=3 \mathrm{~m}^{2} / \mathrm{s}$; $\tau_{0}=0,005$. The values of all the aforementioned coefficients were selected based on the recommendations given in $[17,18]$. 


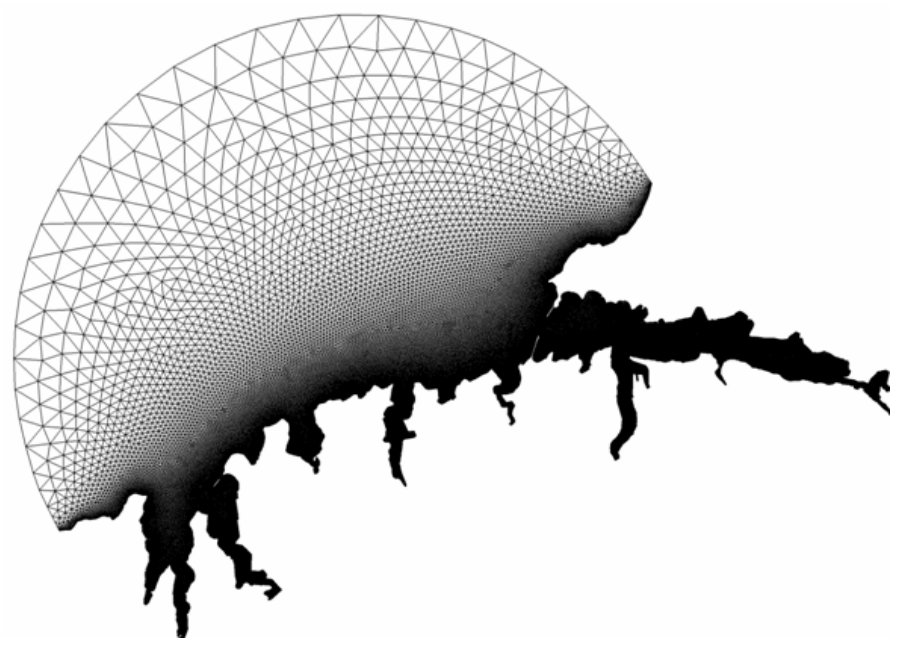

F i g. 3. Unstructured computational grid for modeling seiche oscillations in the system of the Sevastopol bays

As an initial approximation for estimating the periods of eigen oscillations $T_{\mathrm{km}}$ of the bays under study, the formula from [21] was used:

$$
T_{k m}=\frac{4}{\sqrt{g h}} \frac{a b}{\sqrt{(1+2 \mathrm{k})^{2} b^{2}+4 m^{2} a^{2}}},
$$

where $a, b$ and $h$ are the average length, width and depth of the bay; $k=0,1,2$, $\ldots ; m=0,1,2, \ldots$. Calculations by formula (2) give the following estimates of the values of eigen periods for the Sevastopol Bay: 43,8; 14,6; 8,8; 6,3; $2,8 \mathrm{~min}$, for the Quarantine Bay - 11,7; 3,9; 2,3; 1,7; 0,7 min. In [4], a numerical calculation of the Sevastopol Bay eigen periods was carried out taking into account the real profile of the coastline and bathymetry, which gave the following values: $50 ; 22$; 14,$7 ; 12 ; 9,5 ; 7,9 ; 6,4$ min.

Numerical modeling was carried out for three intervals of disturbance periods, covering the range of eigen periods of the Sevastopol and Quarantine bays and calculated using the formula (2):

$$
\Delta T_{1}=30-52, \quad \Delta T_{2}=8-30, \quad \Delta T_{3}=1-15 .
$$

Selection of intervals (in minutes) was carried out for the following reasons: the $\Delta T_{1}, \Delta T_{2}$ ranges contain high-frequency modes of the Black Sea seiches and disturbances caused by the movement of cyclones over the sea and tsunami waves; $\Delta T_{3}$ range - infra-gravity waves and disturbances caused by atmospheric pressure fluctuations.

The calculations were carried out in two stages. At the first stage, zero initial conditions were used. At $t>0$ an open boundary of the computational domain, disturbances of the following form were set

$$
\eta=\frac{a_{0}}{N} \sum_{n=1}^{N} \sin \left(\omega_{n} t+\varphi_{n}\right),
$$


where $a_{0}=10 \mathrm{~cm}$ is the amplitude of oscillations; $N$ is a number of harmonics in a row; $n$ is the harmonics No.; $\omega_{n}=2 \pi / T_{n}$ is the frequency of oscillations, $T_{n}$ is the period of oscillations; $\varphi_{n}$ is the initial phase of oscillations. The oscillation period of each harmonic of series (4) is determined by the expression $T_{n}=T_{\min }+\left(T_{\max }-T_{\min }\right) \delta_{n}$, where $T_{\min }, T_{\max }$ are the minimum and maximum periods of oscillations. The value $\delta_{n}$ represented the increment as $\delta_{n}=(n-1) /(N-1)$. The harmonics number $N$ is determined by the step of discreteness in time between adjacent periods (in the calculations, the step $t_{d}=10 \mathrm{c}$ was used), including the values of the maximum and minimum oscillation periods $N=\left(T_{\max }-T_{\min }\right) / t_{d}+1$. The initial phase of oscillations $\varphi_{n}$ was determined according to the formula $\varphi_{n}=\pi\left(\delta_{n}-1 / 2\right)$.

According to the preliminary numerical experiments, the initial phase does not significantly affect the calculation results. The calculations continued for 3 hours of model time. At the second stage, the boundary condition (4) was replaced by the free passage condition. As the initial data, the fields $U, V$ and $\eta$ were set at $\mathrm{t}=3 \mathrm{hrs}$. The duration of the second stage of the calculations was 4 hours of model time.

\section{The numerical simulation results}

The Sevastopol Bay. Fig. 4-6 show mareograms for points 2, 7 and 9 located in the Sevastopol Bay water area (Fig. 1). Fig. 7 shows the energy spectra of level oscillations for the same points. As can be seen from Fig. 4-7, the level fluctuations generated in the bay on the $\Delta T_{1}$ interval have the highest energy and slower fade away. The period of $48 \mathrm{~min}$ is clearly traced in these oscillations, corresponding to the Helmholtz mode of the Sevastopol Bay. High frequency modes are not generated.
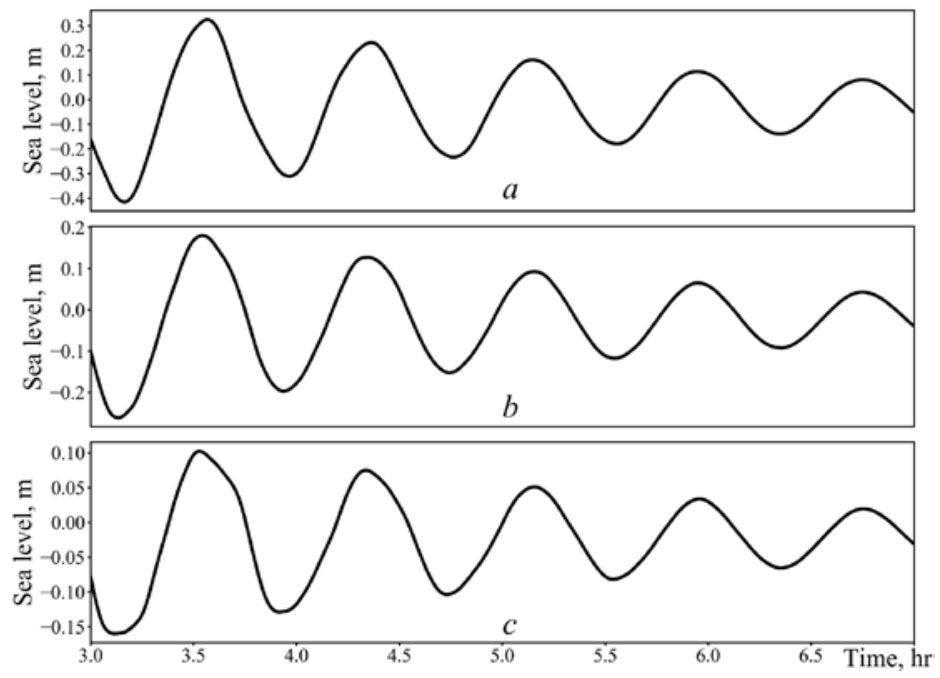

F i g. 4. Mareograms for $\Delta T_{1}: a$ - at point 2; $b$ - at point $7 ; c$ - at point 9 

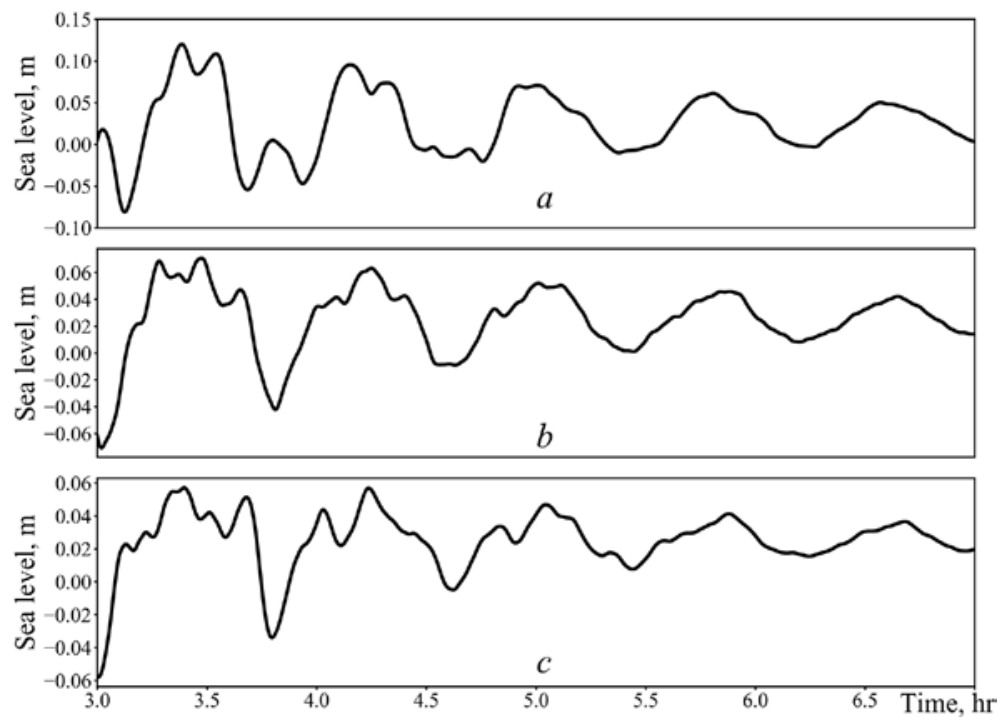

F i g. 5. Mareograms for $\Delta T_{2}: a$ - at point 2; $b$ - at point 7; $c$ - at point 9

On the $\Delta T_{2}$ interval (Fig. 5; 7, $d-f$ ) the oscillation energy generated in the Sevastopol Bay oscillations is an order of magnitude less than on the $\Delta T_{1}$ interval. The Helmholtz mode (48 min period) dominates in the bay. Fast fading (within $1.5 \mathrm{~h}$ (Fig. 5)) high-frequency modes are superimposed on it. Among them, own modes with periods of 16, 22-24; 6; 10 min are most intense; (indicated in descending order of energy contribution). In addition to these modes, oscillation with a period of 11.4 minutes corresponding to the Quarantine Bay Helmholtz mode are recorded throughout the Sevastopol Bay water area.
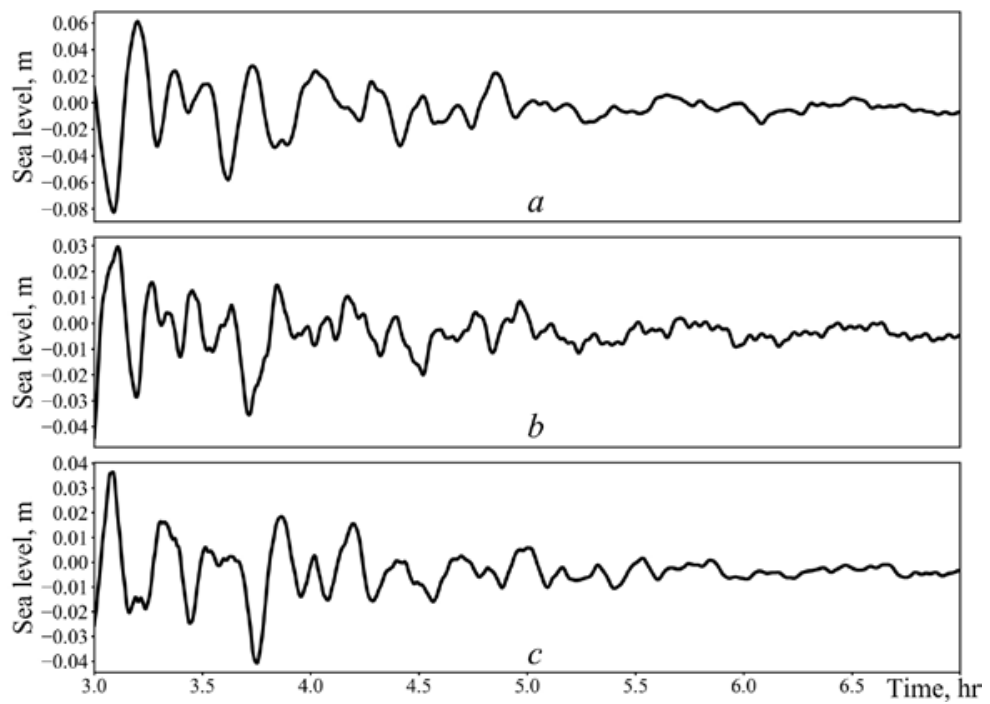

F i g. 6. Mareograms for $\Delta T_{3}$ : $a$ - at point $2 ; b$ - at point $7 ; c$ - at point 9 
On the $\Delta T_{3}$ interval (Fig. 6; 7, $g-i$ ) the maximum energy of oscillations generated in the Sevastopol Bay is 5-10 times less than on the $\Delta T_{2}$. interval. The oscillations fade rather quickly and have the nature of beats (Fig. 6) when several modes comparable in energy level interact. The mode with the period of 16 min prevails over almost the entire bay water area. Other modes with periods of 48; 22; 10 and 6 min, which are eigen modes of the Sevastopol Bay, also stand out (Fig. 7, $g-i$ ). Oscillations with periods of 48 and 6 minutes have the greatest energy of them. The Quarantine Bay Helmholtz mode with a period of 11.4 minutes is also well traced in Sevastopol Bay, in addition to its eigen modes. At the top of the Sevastopol Bay (point 2), the energy of this mode is $64 \%$ of the maximum.
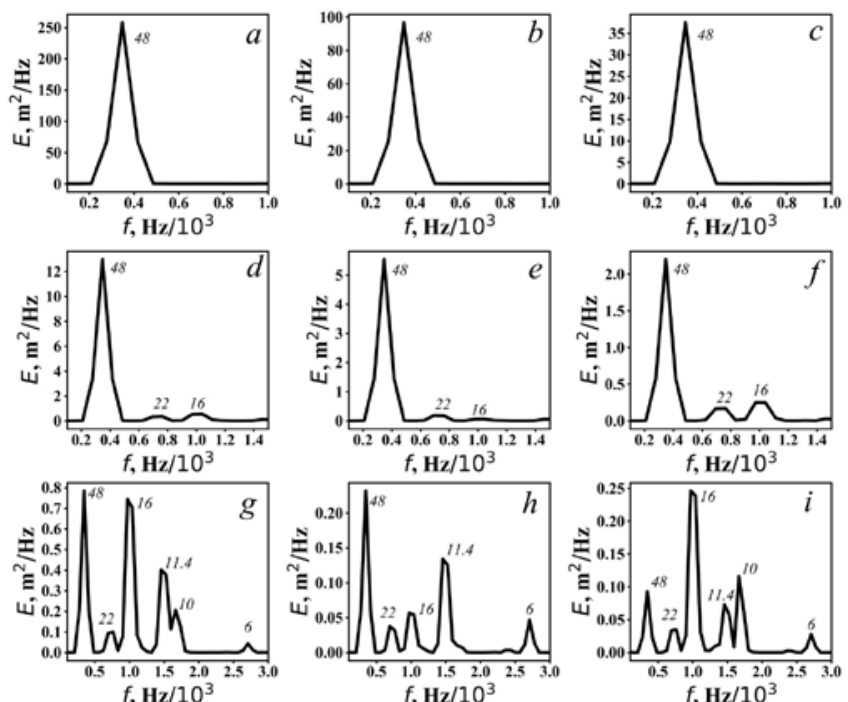

F i g. 7. Energy spectra of level fluctuations in the Sevastopol Bay (the periods (in minutes) are indicated for the major peaks). For the $\Delta T_{1}$ interval: $a$ - at point $1 ; b$ - at point $7 ; c-$ at point 9 . For the $\Delta T_{2}$ interval: $d$ - at point $1 ; e$ - at point $7 ; f-$ at point 9 . For the $\Delta T_{3}$ interval: $g-$ at point $1 ; h-$ at point $7 ; i$ - at point

Additional numerical experiments were carried out to explain the reason leading to the generation of the Sevastopol Bay Helmholtz mode by disturbances whose periods lie in the range of 1-30 min. As disturbances, the liquid boundary oscillations at one of the eigen periods of the Sevastopol Bay were considered 48; 22 and 16 min, and also on two non-resonant periods of 30 and 60 min. Each numerical experiment consisted of two stages. At the first stage, a forced task with zero initial conditions was solved. The calculation duration was 3 hours of model time. At the second stage, with a duration of 4 hours of model time, the problem of free waves with the initial conditions obtained as a result of calculations at the first stage was solved. At the liquid boundary, the condition of the free passage of waves was set. As a result of numerical experiments with forced waves (the first stage), the following was established. In the Sevastopol Bay, a dominant oscillation with a frequency equal to the frequency of the driving force is distinguished in all the cases considered. As well as insignificant local maxima at the Sevastopol Bay 
eigen periods of the Sevastopol Bay, which are less than the disturbance period, take place on the energy spectra.

An analysis of the calculation results for the second stages of numerical experiments showed that after the perturbation stopped, seiche oscillations occurred in the Sevastopol Bay with periods close to those of the eigen modes of the Sevastopol Bay. In this case, there has always been an intense Helmholtz mode of the Sevastopol Bay. This can be explained by the fact that free oscillations on non-resonant periods fade away quickly, as well as by the general property of oscillatory systems: they tend to respond to all types of disturbances with oscillations at the eigen periods of the system, especially on the period of the zero mode. It is also characteristic for an elongated water body with an open narrowed entrance that the Helmholtz mode prevails in it. This is particularly confirmed by observations of the Sevastopol Bay level [2].

A comparative analysis of the simulation results shows that the largest amplitudes of level fluctuations correspond to the $\Delta T_{1}$ interval, and the smallest to the $\Delta T_{3}$ interval. In this case, the maximum range of level fluctuations differ by more than two times. The main feature of the Sevastopol Bay is that for all considered periods of disturbances, the Helmholtz mode is generated in it. It prevails over other modes in the $\Delta T_{1}$ and $\Delta T_{2}$ intervals. This can be explained by the fact that the Sevastopol Bay is quite narrow and long and has a narrowed entrance. As is known [8], in such bays, the Helmholtz mode dominates all other modes and determines the general character of movements in the inner water area. According to field observations [2], in the Sevastopol Bay, seiches with a period corresponding to the Helmholtz mode are observed almost constantly.

As an example in Fig. 8 the sea level positions for the $\Delta T_{2}$ interval in the section passing through points $1-10$ and 14-21 (Fig. 1) are shown. It can be seen that the level fluctuations are in the form of the Helmholtz mode: they are most intense at the top of the bay, do not have nodal lines inside the bay, at the entrance to the bay level variations are insignificant, which indicates the presence of a nodal line of this mode.

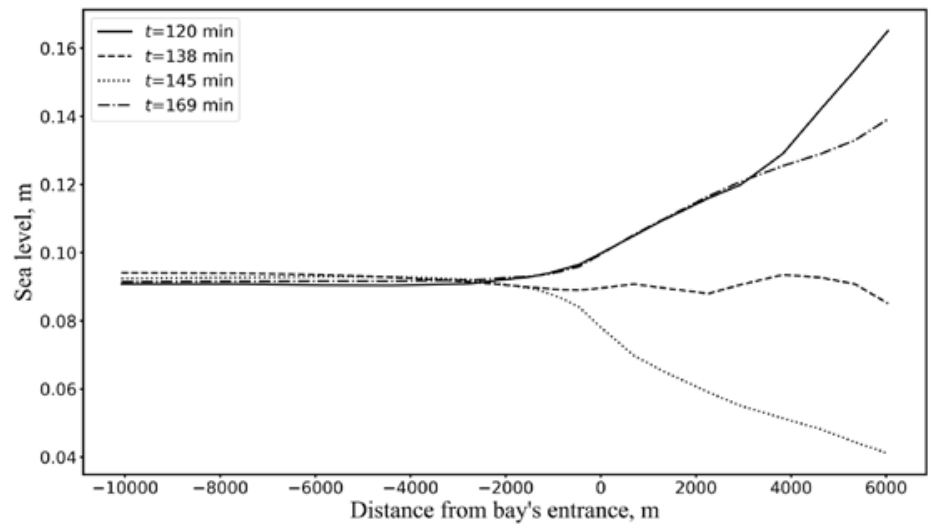

F i g. 8. Level fluctuations for the $\Delta T_{2}$ interval at the section passing along the Sevastopol Bay axis for the characteristic time points within the time interval equal to the Helmholtz mode period. Abscissa of the $0 \mathrm{~m}$ value corresponds to the bay entrance (point 10 in Fig. 1) 
The Quarantine Bay. Below the response of the Quarantine Bay to disturbances of the form (4) is analyzed. There are mareograms for points 11-13 (Fig. 1) for $\Delta T_{1}, \Delta T_{2}, \Delta T_{3}$. intervals on Fig. 9-11. The analysis of these curves shows that the fluctuations in the $\Delta T_{1}$ interval are periodic, and in the $\Delta T_{2}, \Delta T_{3}$ intervals have the beat pattern. The largest ranges of level variations are close to each other on all considered intervals of perturbation periods and are $10-12 \mathrm{~cm}$ at the top of the bay. Seiches do not fade for a long time: oscillations occur for more than 6 hours.

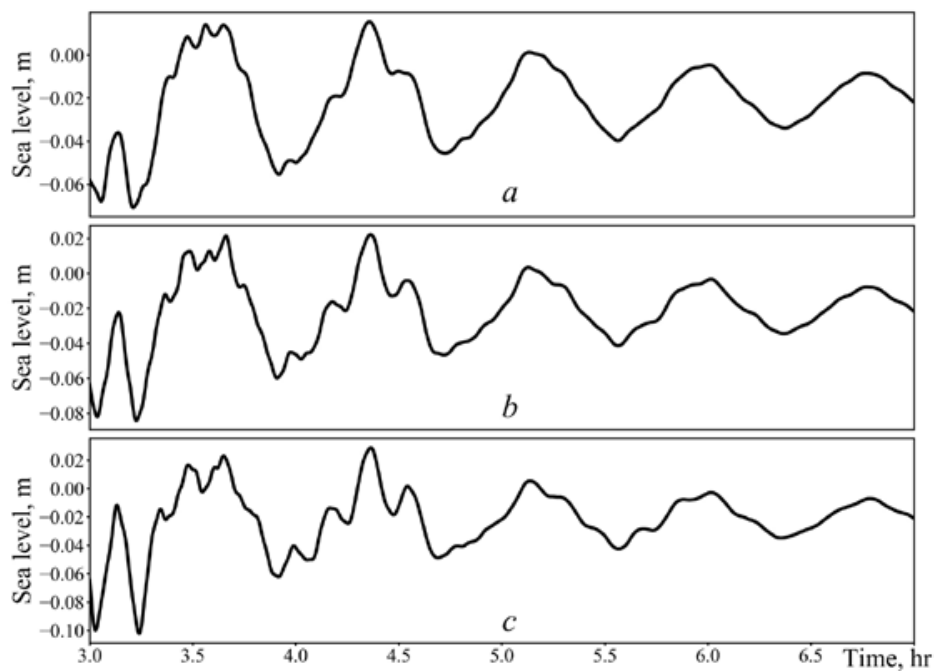

F i g. 9. Mareograms for the $\Delta T_{1}$ interval: $a$ - at point $11 ; b$ - at point $12 ; c$ - at point 13
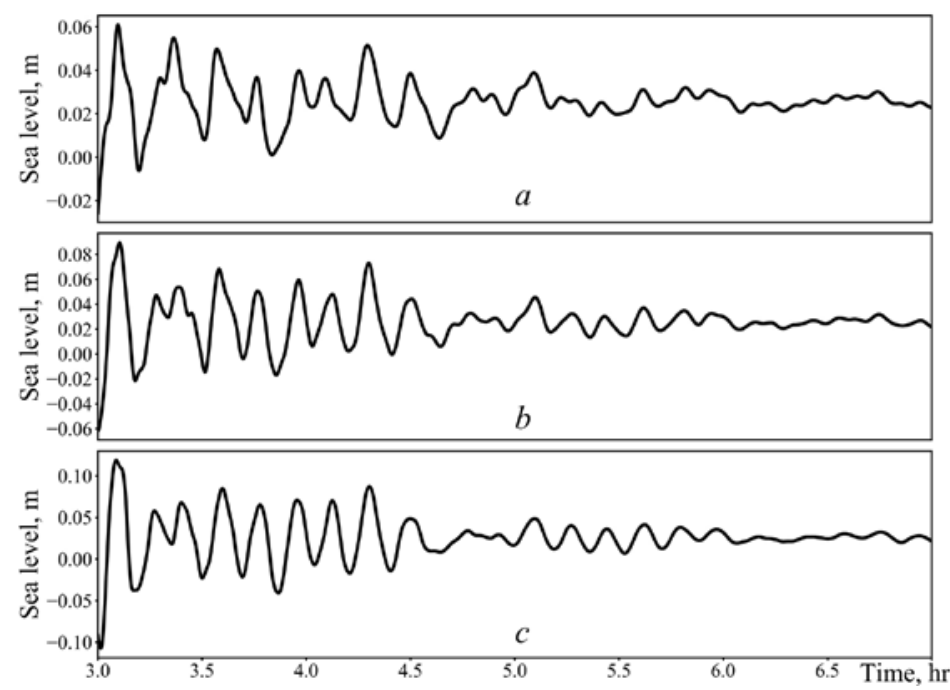

F i g. 10. Mareograms for the $\Delta T_{2}$ interval: $a$ - at point $11 ; b$ - at point $12 ; c$ - at point 13 

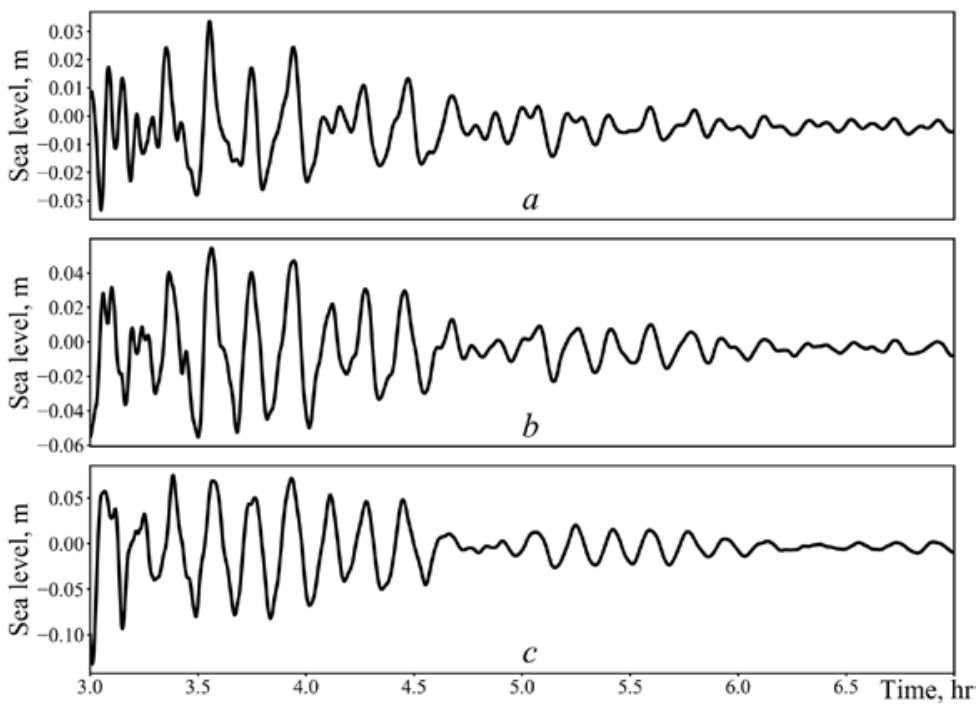

F i g. 11. Mareograms for the $\Delta T_{3}$ interval: $a$ - at point $11 ; b$ - at point $12 ; c$ - at point 13

Fig. 12 shows the energy spectra plotted for points 11-13 for the $\Delta T_{1}, \Delta T_{2}, \Delta T_{3}$. intervals. As can be seen, on the $\Delta T_{1}$ interval the oscillation corresponding to the Helmholtz mode of the Sevastopol Bay dominates. Two local maxima are also distinguished at periods of 11.4 min (the Helmholtz mode of the Quarantine Bay) and 16 min (eigen mode of the Sevastopol Bay). If the period of disturbances lies in the $\Delta T_{2}$ interval, then the mode with a period of 11.4 minutes is most pronounced in the entire water area of the bay. This mode prevails over all other modes throughout the bay, with the exception of the area adjacent to the bay entrance, where the Helmholtz mode of the Sevastopol Bay dominates. In addition to the indicated modes, in the Quarantine Bay modes with periods of 22; 16; 10; 6 min are also distinguished (Fig. 12, $d-f$ ), corresponding to the eigen modes of the Sevastopol Bay.

The $\Delta T_{3}$ interval specific feature is the domination in the bay the Helmholtz mode of Quarantine Bay (period of 11.4 minutes). In the area adjacent to the bay top, a peak is also distinguished at a period of 4.8 minutes, corresponding to the first eigen mode of the Quarantine Bay. In addition to these modes, the fluctuations with periods of $16 ; 10 ; 6$ minutes are monitored in the Quarantine Bay. They are the eigen modes of the Sevastopol Bay. In the $\Delta T_{1}$ interval, the eigen modes of the Quarantine Bay are not practically generated and the Helmholtz mode of the Sevastopol Bay dominates in it. At the $\Delta T_{2}, \Delta T_{3}$ intervals in the Quarantine Bay, the Helmholtz mode of this bay with a period of 11.4 minutes dominates over all modes of seiche oscillations. In the Quarantine Bay, a number of eigen modes of the Sevastopol Bay with periods of 16 and 6 minutes are also distinguished; being the most intense at the bay entrance, as well as a mode with a period of $10 \mathrm{~min}$, which has the highest intensity at the bay top (Fig. 12, i). 

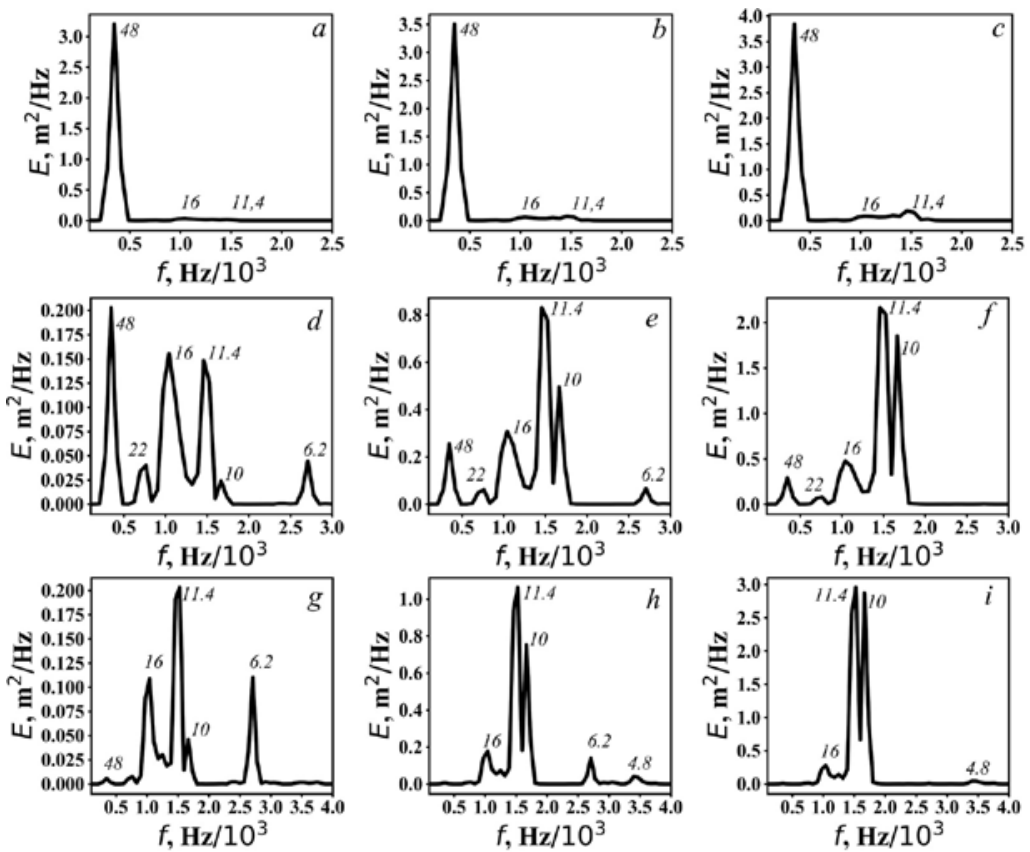

F i g. 12. Energy spectra of level fluctuations in the Quarantine Bay (the periods (in minutes) are indicated for the major peaks). The $\Delta T_{1}$ interval: $a$ - at point $11, b-$ at point $12, c-$ at point 13 . The $\Delta T_{2}$ interval: $d$ - at point $11 ; e-$ at point $12 ; f-$ at point 13 . The $\Delta T_{3}$ interval: $g$ - at point $11 ; h-$ at point $12 ; i-$ at point 13

It should be noted that observation in the bays of eigen mode fluctuations of adjacent bays is known. For example, in the Ciutadella Bay there is a fairly intense Helmholtz mode of the adjacent Platja Gran Bay with a period of 5.5 min, and in the Platja Gran Bay there is a Helmholtz mode of the Ciutadella Bay with a period of $10.5 \mathrm{~min}[12,22]$. A similar picture takes place in the Posyet Gulf in the Sea of Japan. There are two adjacent bays in this bay - the Vityaz (the length, taking into account the Tarantsev Islands and Shultz Cape, is about $3.2 \mathrm{~km}$, average depth $15 \mathrm{~m}$ ) and Troitsa Bay (length $6.15 \mathrm{~km}$, average depth $12 \mathrm{~m}$ ). The shape of these bays is close to rectangular. Calculation of eigen periods according to the formula (2) gives the following values. The Vityaz Bay: 17.7 min (the Helmholtz mode); 5.9; 3.5; 2.5 minutes. The Troitsa Bay: 37.8 min (Helmholtz fashion); 12.6; 7.6; 5.4 minutes. The Vityaz Bay was studied in more detail [14, 15]. As a result of processing the observational data in [14, p. 99; 15, p. 59], a powerful peak was identified over a period of $17.28 \mathrm{~min}$, corresponding to an analytical estimate of the Helmholtz mode period of the Vityaz Bay. In [15, p. 59] the presence of peaks in the Vityaz Bay at periods of 17.2-17.5; 7.5-6.25; 3.5; 2.5 minutes is shown. Values of 17.5; 3.5; 2.5 min periods are in good agreement with the analytical estimates obtained above. The period of 7.5 minutes most likely belongs to the eigen mode of the Troitsa Bay, adjacent to the Vityaz Bay. In [14, p. 98], for the Vityaz Bay, a recording section of a laser demograph containing the response to the earthquake on March 11, 2011 east of Japan is given. In this figure, the third largest peak over a period of about 38 min corresponds to the Helmholtz mode of the Troitsa Bay. 
Penetration into the bay of eigen modes of the adjacent bay is also confirmed by the results of numerical simulation. Thus, for example, in [12] it was established that the Helmholtz mode of the neighboring Platja Gran Bay with a period of $5.5 \mathrm{~min}$ is quite intense in the Ciutadella Bay. In [11], it was shown that in the model basin approximating the Quarantine Bay, the eigen modes of the Sevastopol Bay are stand out.

In [13], based on laboratory experiments, it was established that the following types of oscillations are possible in a system of two closely spaced identical rectangular bays: co-phasic, contra-phasic, a combination of co-phasic and contraphasic (in this case, beats are observed in the bays). If the oscillations are co-phasic in nature, then the energy exchange between the bays is not carried out and it is radiated into the open sea through the entrances to the bays. When the oscillations are of a contra-phasic nature, a periodic exchange of energy occurs between the bays. As a result, such oscillations do not decay for a long time. The periods of co-phasic oscillations are longer than the corresponding eigen periods of the bay, and contra-phasic oscillations are smaller. With increasing distance between the bays, the periods of co-phasic oscillations decreased, and the periods of contraphasic oscillations increased and approached the eigen periods of the bay. In [13], it was also shown the interaction between bays. For this purpose, the seiches were initially generated in one of the bays (the entrance to the second was closed). Then the entrance to the blocked bay was opened, and immediately water level fluctuations having the form of beats appeared in it. Over time, the beats turned into contra-phasic oscillations with respect to the oscillations in the first bay.

Also in [13], the results of a laboratory experiment on modeling the response of adjacent bays to a tsunami wave are presented. This wave action resulted in the co-phasic oscillations generated in both bays. They soon took the form of beats and then turned into contra-phasic oscillations, which did not change their form until complete fading.

The above results of laboratory experiments are in good agreement with the theory of linear coupled oscillators. So, in [23] it was shown that coupled oscillators can perform both co-phasic and contra-phasic oscillations. In commonmode oscillations, the energy exchange between the oscillators does not occur. If the oscillations are out of phase, then the coupling leads to the periodic exchange of energy between the oscillators, and the period of pumping depends on the coupling magnitude [23].

Based on the results of $[13,23]$, the mareograms at points located at the tops of the Sevastopol and Quarantine Bays were analyzed. It was found that as a result of the action of disturbances on the bays in the $\Delta T_{2}$ interval, oscillations with an contra-phasic character are generated in them (Fig. 5, a; 10, $c$ ). When exposed to the $\Delta T_{3}$ interval in the bays, the co-phasic oscillations occur, which then turn into contra-phasic ones (Fig. $6, a ; 11, c$ ). In the case of exposure to the $\Delta T_{1}$ interval in the bays, co-phasic oscillations that do not change their character throughout the entire calculated time interval are generated (Fig. 4, a; 9, $c$ ). As the results of this work show, such "foreign” oscillations can be quite intense. Thus, a significant intensification of "foreign" oscillations takes place for the Helmholtz modes of the Sevastopol and Quarantine Bays, as well as for the eigen mode of the Sevastopol bay with a period of $10 \mathrm{~min}$. 


\section{Conclusions}

Based on numerical modeling, the response of the Sevastopol and Quarantine Bays to sea level disturbances at a remote open boundary are studied. Numerical experiments were carried out for three intervals of periods of disturbing forces: 30 52 min; 8-30 minutes and 1-15 minutes

The influence of the aforementioned disturbances leads to the generation of eigen modes of bays: in the Sevastopol Bay - with periods of $48 ; 22 ; 16 ; 10$; 6 minutes, in the Quarantine Bay - with periods of 11.4; 4.8 minutes The number of generated modes is determined by the interval of disturbance periods.

The Sevastopol and Quarantine Bays have a mutual effect on each other due to the disturbance energy exchange through their entrances. This effect is expressed in the penetration of oscillations with periods of eigen modes of each of the bays into the neighboring bay. In this case, the intensity of the eigen modes of the Sevastopol Bay (in particular, with periods of 48; $10 \mathrm{~min}$ ) penetrating the Quarantine Bay can exceed the intensity of the eigen modes of the Quarantine Bay. Seiches with the largest amplitudes in both bays are caused by disturbances with periods ranging within 30-52 min.

\section{REFERENCES}

1. Ivanov, V.A., Ovsyany, E.I., Repertin, L.N., Romanov, A.S. and Ignatyeva, O.G., 2006. Hydrological and Hydrochemical Regime of the Sevastopol Bay and Its Changes under Influence of Climatic and Anthropogenic Factors. Sevastopol: ECOSI-Gidrofizika, 90 p. (in Russian).

2. Goriachkin, Yu.N., Ivanov, V.A., Repetin, L.N. and Khmara, T.N., 2002. [Seiches in Sevastopol Bay]. In: UHMI, 2002. Trudy UkrNIGMI [Proceedings of UHMI]. Kiev: UHMI. Vol. 250, pp. 342-353 (in Russian).

3. Morozov, A.N., Lemeshko, E.M., Shutov, S.A. and Zima V.V., 2012. Currents in the Sevastopol Bay from ADCP observations (June, 2008). Morskoy Gidrofizicheskiy Zhurnal, (3), pp. 31-43 (in Russian).

4. Chekhov, V.N. and Lushnikov, V.O., 2015. [To the Estimates of Seiches in Bays of Crimea by Finite Element Method]. Dinamicheskie Sistemy = Dynamical Systems, 5(1-2), pp. 93-102 (in Russian).

5. Mikhailova, E.N. and Shapiro, N.B., 2005. Simulation of the Circulation and Space Structure of Thermohaline Fields in the Sevastopol Bay with Regard for the Actual External Data (Winter, 1997). Physical Oceanography, 15(2), pp. 118-132. https://doi.org/10.1007/s11110005-0035-0

6. Belokopytov, V.N., Kubryakov, A.I. and Pryakhina, S.F., 2019. Modelling of Water Pollution Propagation in the Sevastopol Bay. Physical Oceanography, 26(1), pp. 3-12. doi:10.22449/1573-160X-2019-1-3-12

7. Fomicheva, L.A., Rabinovich, A.B. and Demidov, A.N., 1991. [Tsunami in the Black Sea]. In: [Hydrometeorology and Hydrochemistry of the USSR Seas. T. IV. The Black Sea. Vol. 1. Hydrometeorological Studies]. Saint Petersburg: Gidrometeoizdat, pp. 352-354 (in Russian).

8. Rabinovich, A.B., 1993. [Long Gravitational Waves in Ocean: Capture, Resonance, Radiation]. Leningrad: Gidrometeoidat, 322 p. (in Russian).

9. Balinets, N.A. and Khmara, T.V., 2006. Phenomena of Harbor Seiches in the Sevastopol Bays. In: In: MHI, 2006. Ekologicheskaya Bezopasnost' Pribrezhnykh i Shel'fovykh Zon i Kompleksnoe Ispol'zovanie Resursov Shel'fa [Ecological Safety of Coastal and Shelf Zones and Comprehensive Use of Shelf Resources]. Sevastopol: ECOSI-Gidrofizika. Iss. 14, pp. 204-208 (in Russian). 
10. Manilyuk, Yu.V., 2018. Seiches and Harbor Oscillations in the Sevastopol Bay. Ecological Safety of Coastal and Shelf Zones of Sea, (3), pp. 4-12. doi:10.22449/2413-5577-2018-3-4-12 (in Russian).

11. Manilyuk, Yu.V., Lazorenko, D.I. and Fomin, V.V., 2019. Resonance Oscillations on the System of Adjacent Bays. Physical Oceanography, 26(5), pp. 374-386. doi:10.22449/1573-160X-2019-5-374-386

12. Liu, P.L.-F., Monserrat, S., Marcos, M. and Rabinovich, A.B., 2003. Coupling between Two Inlets: Observation and Modeling. Journal of Geophysical Research: Oceans, 108(C3), 3069. https://doi.org/10.1029/2002JC001478

13. Nakano, M. and Fujimoto, N., 1987. Seiches in Bays Forming a Coupled System. Journal of the Oceanographical Society of Japan, 43(2), pp. 124-134. https://doi.org/10.1007/BF02111888

14. Dolgikh, G.I., Dolgikh, S.G., Smirnov, S.V., Chupin, V.A., Shvets, V.A. and Yakovenko, S.V., 2011. Infrasound Oscillations in the Sea of Japan. Doklady Earth Sciences, 441(1), pp. 1529-1532. doi:10.1134/S1028334X11110031

15. Dolgikh, G.I., Budrin, S.S., Dolgikh, S.G., Plotnikov, A.A., Chupin, V.A., Shvets, V.A. and Yakovenko, S.V., 2016. Free Oscillations of Water Level in the Posyet Gulf Bays (the Sea of Japan). Russian Meteorology and Hydrology, 41(8), pp. 559-563. https://doi.org/10.3103/S1068373916080057

16. Dolgikh, G.I., Kovalev, D.P. and Kovalev, P.D., 2019. Excitation of Under-Ice Seiches of a Sea Port of the Sea of Okhotsk. Doklady Earth Sciences, 486(2), pp. 651-653. doi:10.1134/S1028334X19060011

17. Luettich, R.A., Westerink, J.J. and Scheffner, N.W., 1992. ADCIRC: An Advanced ThreeDimensional Circulation Model for Shelves Coasts and Estuaries. Report 1: Theory and Methodology of ADCIRC-2DDI and ADCIRC-3DL. Washington, DC: U.S. Army Engineers Waterways Experiment Station, 137 p. Available at: https://archive.org/details/DTIC_ADA261608 [Accessed: 23 May 2020].

18. Luettich, R.A. and Westerink, J.J., 2004. Formulation and Numerical Implementation of the 2D/3D ADCIRC Finite Element Model Version 44.XX. [online] Available at: https://adcirc.org/files/2018/11/adcirc_theory_2004_12_08.pdf [Accessed: 23 May 2020].

19. Fomin, V.V., Lazorenko, D.I. and Ivancha, E.V., 2017. Numerical Simulation of Seiches in the Balaklava Bay. Ecological Safety of Coastal and Shelf Zones of Sea, (3), pp. 32-39 (in Russian).

20. Fomin, V.V., Lazorenko, D.I. and Fomina, I.N., 2017. Numerical Modeling of Water Exchange through the Kerch Strait for Various Types of the Atmospheric Impact. Physical Oceanography, (4), pp. 79-89. doi:10.22449/1573-160X-2017-4-79-89

21. Maniliuk, Yu.V. and Fomin, V.V., 2017. Seiche Oscillations in a Partially Enclosed Basin. Ecological Bulletin of Research Centers of the Black Sea Economic Cooperation, (3), pp. 73-83 (in Russian).

22. Rabinovich, A.B., 2009. Seiches and Harbor Oscillations (Chapter 9), In: Y.C. Kim, ed., 2009. Handbook of Coastal and Ocean Engineering. Singapoure: World Scientific Publ., pp. 193-236. https://doi.org/10.1142/9789812819307_0009

23. Rabinovich, M.I. and Trubetskov, D.I., 1984. Introduction to the Theory of Oscillations and Waves. Moscow: Nauka, 432 p. (in Russian).

About the authors:

Yury V. Manilyuk, Senior Research Associate, Marine Hydrophysical Institute of RAS (2 Kapitanskaya Str., Sevastopol, 299011, Russian Federation), ResearcherID: P-6662-2017, ORCID ID: 0000- 0002-5752-7562, uvmsev@yandex.ru

Dmitry I. Lazorenko, Research Associate, Marine Hydrophysical Institute of RAS (2 Kapitanskaya Str., Sevastopol, 299011, Russian Federation), Ph. D. (Tech. Sci.), ResearcherID: J-1925-2015, ORCID ID: 0000-0001-7524-565X, d.lazorenko@mhiras.ru 
Vladimir V. Fomin, Head of the Department of Computational Technologies and Mathematical Modeling, Marine Hydrophysical Institute of RAS (2 Kapitanskaya Str., Sevastopol, 299011, Russian Federation), Dr. Sci (Phys.-Math.), ResearcherID: H-8185-2015, ORCID ID: 0000-0002-9070-4460, v.fomin@mhi-ras.ru

Contribution of the authors:

Yuriy V. Manilyuk - problem statement, analysis of the calculation results, writing and updating the paper text, discussion of the results, formulation of conclusions

Dmitriy I. Lazorenko - carrying out the numerical calculations, algorithmic processing of the calculation results, preparation of the figures, discussion of the calculation results

Vladimir V. Fomin - problem statement, adjustment of the numerical model, editing of the paper text, consulting support, discussion of the calculations results, formulation of conclusions

All the authors have read and approved the final manuscript.

The authors declare that they have no conflict of interest. 